\title{
El ritmo poético de González Martínez
}

\author{
INTRODUCCION
}

$F^{L}$ estudio de la silabificación y la versificación de Enrique González Martínez revela que existe gran armonía entre sus temas y la versificación con que les da forma. Como en su ideología, vira entre dos polos. En sus poesías serias y líricas predominan los endecasílabos y alejandrinos, con formas métricas de sonetos y de redondillas. Estas dos épocas de intensidad lírica se extienden desde 1903 hasta 1921 y desde 1935 hasta 1948.

E1 polo opuesto lo encontramos en el período de 1921 a 1935 , cuando abandona estas formas tradicionales y hace gran uso de formas con rima asonante y versos de gran irregularidad. En este estudio definimos como estrofa irregular la que tiene más de tres medidas. Por ejemplo, una estrofa que tiene de 5-7-9-3, la llamamos irregular porque no cae dentro de ningún molde estrófico.

Este período de experimentación en formas irregulares se distingue por el uso de temas que hemos llamado "poesías modernas" y "humorísticas".

La primera sección del estudio presenta las diferentes formas métricas en la poesía de González Martínez; la segunda presenta las diferentes formas silábicas; la tercera establece la relación entre los temas y la versificación, y la cuarta consiste en un análisis estadístico, tomo por tomo, de la frecuencia de estas formas silábicas y métricas.

Con la excepción de Jardines de Francia, tráducciones del francés que González Martínez llama versiones, se incluyen en el estudio todas las poesías de González Martínez y dan un total de 672. 


\section{LA RIMA}

En este número de poesías los sonetos predominan, con un número de 226 o sea el 34\%. Siguen las rimas asonantes, con 174 poesías, o sea el $26 \%$. Si agregamos al soneto la redondilla, otra poesía tradicional, que es de una frecuencia de $16 \%$, podemos afirmar que en la versificación del Hombre del buho predominan el soneto y la redondilla, con un porciento de 50 .

El otro $50 \%$ de la rima de González Martínez consiste en todas las rimas que los modernistas popularizaron y muchas combinaciones noveles de ellas. En la cuarta sección damos su frecuencia, en detalle; pero sigue aquí una lista de ellas:

Rimas

Sonetos

Redondillas

Asonantes

Décimas

Serventesios

Quintillas

Liras

Silvas

Tercetos

Pareados

Séptimas

Verso Libre

Octavas

Consonantes $y$

Cuartetos
Combinaciones de versos menores

Terceto: Redondilla

Redondilla: Pareados

Redondilla: Sextinas

Redondilla: Sextinas

Redondilla: Serventesios

Redondilla: Quintillas

Quintilla: Pareados

Quintilla: Serventesios

Redondilla: Asonantes

Quintilla: Sextinas

Quintilla: Tercetos

Tercetos: Serventesios

Tercetos: Cuartetos

Quintilla: Redondilla: Pareados

Redondilla: Serventesios: Pareados

Quintilla: Séptimas: Pareados y

Quintilla: Sextinas: Tercetos.

El soneto. Por la gran frecuencia del soneto en la poesía de González Martínez, podemos calificarle de sonetista por antonomasia. Hemos encontrado cinco variantes del soneto:

Tipo de soneto

Número 1

Número 2

Número 3

Número 4

Número 5
Rima

abbaabba cdcded

abbaabba ccdeed

abbaabba cdecde

abbaabba ccdede

abababab ccdeed
Número

$$
\begin{array}{r}
36 \\
172 \\
7 \\
2 \\
9
\end{array}
$$


En Vilano al viento (pág. 34) se encuentra un ejemplo del soneto número uno:

Victoria sobre la Muerte

¿Triunfa la muerte al fin de la jornada?

El aliento vital de la doctrina

que separó la rosa de la espina

¿será ventisca en gleba congelada?

El que siembra verdad deja preñada

la tierra con simiente que germina

o el soplo de la ráfaga asesina

muda en estéril campo la llanada?...

i No propale la muerte su victoria!

Si hay un vigía en el fanal que viette perenne luz en vida transitoria;

si el verbo se difunde y se convierte en el propio guardián de tu memoria, ¿ dónde está la victoria de la muerte?

El soneto número dos es el de mayor frecuencia. Un bello ejemplo en alejandrinos se halla en Silénter:

\section{Como la barca es mía...}

Como la barca es mía, como navego solo, frívolamente vago donde el azar me inclina, lo mismo entre los rudos tifones de la China que entre las moles álgidas del congelado polo.

Arrojo el ancla a veces, y mi pendón tremolo albo como el plumaje de algún ave marina; me halagan las sirenas con su canción divina, Neptuno me adormece y me acaricia Eolo.

Tú que a lo lejos miras pasar mi carabela y que de pie en la proa me ves que a toda vela a cielo y mares lanzo mi loco desafío, no mi bajel detengas. Tu timidez en vano iza el pañuelo al viento con temblorosa mano... Yo gusto de ir a solas y mi velero es mío.

(Obras completas, pág. 46.)

"Primavera" es un ejemplo del soneto número tres y se encuentra en Preludios: 
Amada, ven. Del campo la verdura salpican ya las tempraneras flores, y el ejambre de pájaros cantores sus trinos lanza en la arboleda oscura.

Mira, desde el cenit el sol fulgura en torrentes de luz abrasadores, $y$ es una alegre fiesta de colores al ósculo del viento la llanura.

Entre las redes del amor opresos, miraremos pasar en dulce halago del rio paternal las claras linfas,

$y$ al estallar de mis amantes besos, verás bañarse en el azul del lago blancas, desnudas y en tropel las ninfas.

(Preludios, Lirismos, Silénter, Los senderos ocultos, Ed. de A. Castro Leal, pág. 87.)

El soneto número cuatro es de menor frecuencia. "Intus" de Los senderos ocultos es uno de los dos únicos sonetos de esta versificación:

Te engañas, no has vivido... No basta que tus ojos se abran como dos fuentes de piedad, que tus manos se posen sobre todos los dolores humanos ni que tus plantas crucen por todos los abrojos.

Te engañas, no has vivido mientras tu paso incierto surque las lobregueces de tu interior a tientas; mientras, en un impulso de sembrador, no sientas fecundado tu espíritu, florecido tu huerto.

Hay que labrar tu campo, divinizar la vida, tener con mano firme la lámpara encendida sobre la eterna sombra, sobre el eterno abismo...

$Y$ callar, mas tan hondo, con tan profunda calma, que absorto en la infinita soledad de ti mismo, no escuches sino el vasto silencio de tu alma.

(Obras completas, pág. 118.)

$Y$ del soneto número cinco, del cual hay nueve ejemplos, of recemos :

Mañana los poetas... 
Mañana los poetas cantarán en divino verso que no logramos entonar los de hoy; nuevas constelaciones darán otro destino a sus almas inquietas con un nuevo temblor.

Mañana los poetas seguirán su camino absortos en ígnota y extraña floración, $\mathrm{y}$ al oír nuestro canto, con desdén repentino echarán a los vientos nuestra vieja ilusión.

$Y$ todo será inútil, $y$ todo será en vano; será el afán de siempre y el idéntico arcano y la misma tiniebla dentro del corazón.

$Y$ ante la eterna sombra que surge y se retira, recogerán del polvo la abandonada lira y cantarán con ella nuestra misma canción.

(Obras completas, pág. 185.)

En la forma del soneto encuentra González Martínez el vehículo más adecuado a su genio poético. Poeta que condensa temas por el laborioso proceso de estilización, encuentra como un orfebre en el poema de cortas dimensiones el mejor medio de expresar su lírica; ya sea la preceptiva retórica de sus primeras poesías, ya la queja lírica y agonizante ante la muerte.

$Y$ en la evolución del soneto se ve, como en toda la forma poética de González Martínez, la tendencia central hacia una sencillez expresiva. Abandona la retórica de Preludios y Lirismos y constantemente labora para expresarse en una forma sencilla; poesía que es ya hablada y no cantada, pero que no desdeña la fina selección del vocablo. $Y$ este es uno de los factoers que dan a su poesía una nota personal distinguida. Compárese "Victoria sobre la muerte" con "Pálida" de Preludios:

Tu palidez marmórea y enfermiza es el mágico filtro que enamora; iy esa sensualidad que te devora, y esa sed de pasión que te electriza!

Como el ave que, muerta, en su ceniza se levanta de nuevo t'riunfadora, tal surge la pasión abrasadora de tu figura blanca y enfermiza.

En tu cuerpo de Venus demacrada se esconde una vestal aprisionada que el sacro fuego del placer atiza. 
Para la prosa de la vida, muerta, sólo para el amor está despierta tu palidez marmórea y enfermiza.

(Preludios, etc. Ed. de Castro Leal, pág. 11.)

"Victoria" expresa el triunfo de la idea sobre la muerte, una rotunda afirmación de la inmortalidad del poeta por medio de su obra. $Y$ esta idea lírica se expresa con sencillez, sin metáforas retorcidas, como el comparar en "Pálida" a una muerta con el Ave Fénix, o con una "Venus demacrada".

Asonantes. La cuarta parte $(26 \%)$ de la poesia de González Martínez que hemos estudiado está asonantada. La emplea con mayor frecuencia en el período de 1921-1935 y está relacionada con el uso de versos irregulares.

Estas poesías asonantadas expresan con mayor frecuencia temas de tendencias contemporáneas o humorísticas, como lo puntualizaremos en la próxima sección. Pero así como González Martínez es maestro de la rima, lo es también del asonante y lo emplea en poesías con ritmo interno y temas líricos. El mejor ejemplo se halla en "Iglesia de barrio". Esta poesía tiene la repetición libre, pero rítmica, con acentos libres de la afectación matemática de la poesía tradicional. Es lástima que González Martínez no haya explotado este género de poesías que estilizan temas americanos. Citamos sólo dos estrofas de "Iglesia de barrio", para dar una idea de este ritmo interno y de la sencillez de expresión en los asonantes:

Iglesia, pobre iglesia

de los desamparados, en que un Cristo deforme y caricaturesco

abre lós brazos;

triste iglesia minúscula

de barrio

que pareces un ave macilenta

que cobija polluelos desplumados...

( $\mathrm{Tu}$ pequeñez se yergue altivamente

sobre los techos bajos...)

No tienes el brillante oro de las basílicas;

hay en tus losas gélidas hoyancos, y domingo a domingo, sobre el coro tose un órgano asmático. 
Tan sólo dos campanas

tiene tu campanario:

una, cascada y sorda, con que llaman a misa;

otra, para el rosario.

(Obras completas, pảg. 304.)

"En "Iglesia de barrio" la idea poética y el ambiente creado por el Hombre del buho gobiernan la sencillez de la forma y de la métrica. El mismo vocablo poético es humilde y libre de toda afectación. Hay completa armonía con el tema y la forma.

\section{SILABIFICACION}

Como la rima, la silabificación de González Martínez sigue el mismo sendero. Sin contar las combinaciones con sílabas de once, el endecasílabo comprende el $35 \%$ de su poesía, y si agregamos el alejandrino, llegamos a un total de 58\%. Podemos afirmar que González Martínez piensa en alejandrinos y endecasílabos.

En el polo extremo se hallan los versos de medida irregular que hemos titulado "irregulares". y dan un total del $20 \%$ de su obra total.

La constelación de la medida de versos del Hombre del buho sigue la tendencia modernista y por su variedad es comparable a la combinación de rimas menores suyas.

En sus períodos primero y tercero, de 1903-1921 y 1921-1935 respectivamente, usa con más frecuencia endecasilabos y alejandrinos. En el segundo período, de 1921-1935, el de más experimentación, usa las combinaciones de dos medidas y versos irregulares, con más frecuencia. Damos en seguida la lista completa de versos y combinaciones, en orden numérico:

$6 ; 7-5 ; 7-8 ; 7-9,7-11$ у $7-12$.

$8: 8-4 ; 8-5 ;$ y $8-10$.

$9: 9-3 ; 9-5 ; 9-11 ; 9-13 ;$ y $9-14$.

$10 ;$ y $10-14$.

$11 ; 11-4 ; 11-5 ; 11-7 ;$ y $11-9$.

$12 ;$ y $12-6$.

$14 ; \mathrm{y} 14-8$.

16.

17.

Irregulares. 


\section{LA VERSIFICACION $\mathrm{Y}$ LOS TEMAS POETICOS}

Nos toca ahora puntualizar este ritmo poético de González Martínez. Postulamos como factores relacionados la forma del soneto con el verso de once sílabas y el asonante con versos irregulares. De 1903 a 1921 González Martínez emplea el soneto y el endecasílabo con mayor frecuencia. Y desde 1935 a 1948 repite otra vez esta predominante frecuencia de sonetos y endecasílabos.

En el segundo período, 1921-1935, emplea asonantes y versos irregulares, con la misma relación estrecha que existe entre el soneto y el endecasilabo llegando a la cumbre en 1925 con una frecuencia de $70 \%$.

Con el crecimiento de la frecuencia del soneto desaparece el asonante, y viceversa. Por ejemplo, en 1907 usa $88 \%$ de sonetos y sólo $3 \%$ de asonantes y en 1925 usa $64 \%$ de asonantes e inversamente cero número de sonetos. $\mathrm{Y}$ al final de este estudio, en 1948, usa $44 \%$ de sonetos y sólo $8 \%$ de asonantes.

Respecto al uso de endecasílabos y versos irregulares, en 1907 usa el $88 \%$ de endecasílabos y el $1 \%$ de versos irregulares. En 1925 , la cifra mayor es de $72 \%$ de versos irregulares y $3 \%$ de endecasílabos. Y vuelve en 1948 a la misma tendencia del principio: usa $65 \%$ de sonetos y sólo $5 \%$ de versos irregulares.

Estas cifras prtueban que el ritmo poético de González Martínez se divide en los tres períodos que ya hemos mencionado: 1) 19031921 , 2) 1921-1935 y 3) 1935-1948. Lo cual es de importancia matemática, pero no estética, si estas divisiones no pueden ser relacionadas con los temas usados en estos respectivos períodos.

Afortunadamente, hemos encontrado una relación casi directa entre el empleo de estos factores y los temas:

1) El periodo de 1903-1921 contiene todos los experimentos iniciales del poeta en Preludios y Lirismos, seguidos por una intensificación lírica y predominante desde Silénter, 1908, hasta La palabra del viento, 1921. Basta citar los títulos de las otras obras de este período, para comprobar esta aserción: El libro de la fuerza, de la bondad y del ensueño, 1917 ; Parábolds y otros poemas, 1918, y La palabra del viento, 1921. 
2) Desde 1921 hasta 1935, se encuentran con mucha frecuencia las poesías contemporáneas que hemos llamado "modernas", y también las humorísticas. La mayoría son poemas cortos y en asonante con versos irregulares. La importancia del presente estudio consiste en mostrar esta flexibilidad de González Martínez, al adoptar la libertad de forma con la liberación de sus propios temas que ya se habian fijado con bastante repetición.

3) El tercer período, de 1925 a 1948, cubre un retorno a las formas tradicionales del soneto y la redondilla, con empleo de versos de once y catorce sílabas y simultáneamente el abandono casi total de versos irregulares y rimas asonantes. $\mathrm{Y}$ como apuntamos en la sección titulada "El cielo" es el período de más intensidad lírica de González Martínez. La mayoría de sus poesías de este tercer periodo están dedicadas a ese anhelo de triunfar sobre la muerte, de juntarse con los seres amados, y por el amor, vencer la muerte.

Resumen. González Martínez es más modernista en la forma que en los temas. Es modernista, si se considera su forma poética de rebeldia ante los moldes tradicionales. Es también modernista por las innovaciones en el uso de estos mismos moldes usados idénticamente por los otros poetas modernistas.

De importancia es subrayar el empleo del soneto en temas serios y la flexibilidad con que usa asonantes, en temas más ligeros y frívolos.

Es también importante para nuestro estudio la consideración de que el maridaje con este proceso flexible de forma y tema que le conduce a rango único entre los grandes líricos persiste en toda su obra. La constante tendencia de dar a su vocablo una sencillez de expresión, llega a la cumbre en el momento más lírico de su obra.

En círculo dantesco, el Hombre del buho desafía la locura del mundo en pos de guerra y conquista la muerte por el camino del amor.

José Manuel Topete, University of Florida. 
